\title{
Risk of Recurrent Adverse Outcomes in Gestational Diabetes: a Retrospective Cohort Study
}

\author{
Sue Lynn Lau ${ }^{1}$, Alex Chung ${ }^{2}$, Joanna Kao ${ }^{1}$, Susan Hendon ${ }^{3}$, Wendy Hawke ${ }^{4}$, and Sue Mei \\ $\mathrm{Lau}^{4}$ \\ ${ }^{1}$ University of Western Sydney - Campbelltown Campus \\ ${ }^{2}$ University of New South Wales Prince of Wales Clinical School \\ ${ }^{3}$ Blacktown and Mount Druitt Hospital \\ ${ }^{4}$ The Royal Hospital for Women
}

June 24, 2021

\begin{abstract}
Objective: Compare the risk of recurrent adverse delivery outcome (ADO) or adverse neonatal outcome (ANO) between consecutive gestational diabetes (GDM) pregnancies. Design: Retrospective cohort Setting: Sydney, Australia Population or Sample: 424 pairs of consecutive singleton GDM pregnancies, 2003-2015 Main Outcome Measures:. ADO: instrumental delivery and emergency Caesarean. ANO: large for gestational age (LGA), small for gestational age (SGA), and composite ANO (LGA/SGA/stillbirth/neonatal death/shoulder dystocia). Methods: Using each pregnancy pair ("index" and "subsequent" pregnancy), we calculated ADO and ANO rates and determined risk factors for subsequent pregnancy outcomes (multivariate regression). Results: Subsequent pregnancies had higher rates of elective Caesarean $(30.4 \%$ vs $17.0 \%, \mathrm{p}<0.001)$ and lower rates of instrumental delivery ( $5 \%$ vs $13.9 \%, \mathrm{p}<0.001)$, emergency Caesarean $(7.1 \%$ vs $16.3 \%, \mathrm{p}<0.001)$ and vaginal delivery $(62.3 \%$ vs $66.3 \%, \mathrm{p}=0.01)$. ANO rates in index and subsequent pregnancies did not differ. Index pregnancy adverse outcome was associated with a higher risk of repeat outcome: RR 3.09 (95\%CI:1.30, 7.34) for instrumental delivery, RR 2.20 (95\%CI:1.06, 4.61) for emergency Caesarean, RR 4.55 (95\%CI:3.03, 6.82) for LGA, RR 5.01 (95\%CI:2.73, 9.22) for SGA and RR 2.10 (95\%CI:1.53, 2.87) for composite ANO). The greatest risk factor for subsequent LGA (RR 3.13 (95\%CI:2.20, 4.47)), SGA (RR $4.71(95 \% \mathrm{CI}: 2.66,8.36)$ ) or composite ANO (RR 2.01 (95\% CI:1.46, 2.78)) was having the same outcome in the index pregnancy. Conclusions: Women with GDM and an adverse outcome are at very high risk of the same complication in their subsequent GDM pregnancy, representing a high-risk group that should be targeted for directed management over routine care.
\end{abstract}

\section{Title:}

Risk of Recurrent Adverse Outcomes in Gestational Diabetes: a Retrospective Cohort Study

\section{Authors:}

Sue Lynn Lau ${ }^{1,2}$, Alex Chung ${ }^{3}$, Joanna Kao ${ }^{2}$, Susan Hendon ${ }^{2}$, Wendy Hawke ${ }^{4}$, Sue Mei Lau ${ }^{3,4}$

$\mathrm{AC}$ and JK have contributed equally to this study.

${ }^{1}$ University of Western Sydney, Campbelltown Campus, NSW, Australia

2 Blacktown-Mount Druitt Hospital, NSW, Australia

3 The Prince of Wales Clinical School, UNSW, Randwick, NSW, Australia

4 The Royal Hospital for Women, Randwick, NSW, Australia

\section{Corresponding Author:}


Sue Mei Lau

Diabetes and Endocrinology, Prince of Wales Hospital

Barker St, Randwick

NSW, Australia 2031

Ph: +61 293824602

suemei.lau@health.nsw.gov.au

\section{Short running title:}

Recurrent adverse outcomes in gestational diabetes

\section{Abstract:}

Objective: Compare the risk of recurrent adverse delivery outcome (ADO) or adverse neonatal outcome (ANO) between consecutive gestational diabetes (GDM) pregnancies.

Design: Retrospective cohort

Setting: Sydney, Australia

Population or Sample: 424 pairs of consecutive singleton GDM pregnancies, 2003-2015

Main Outcome Measures: . ADO: instrumental delivery and emergency Caesarean. ANO: large for gestational age (LGA), small for gestational age (SGA), and composite ANO (LGA/SGA/stillbirth/neonatal death/shoulder dystocia).

Methods: Using each pregnancy pair ("index" and "subsequent" pregnancy), we calculated ADO and ANO rates and determined risk factors for subsequent pregnancy outcomes (multivariate regression).

Results: Subsequent pregnancies had higher rates of elective Caesarean $(30.4 \%$ vs $17.0 \%, \mathrm{p}<0.001)$ and lower rates of instrumental delivery ( $5 \%$ vs $13.9 \%, \mathrm{p}<0.001)$, emergency Caesarean $(7.1 \%$ vs $16.3 \%, \mathrm{p}<0.001)$ and vaginal delivery $(62.3 \%$ vs $66.3 \%, \mathrm{p}=0.01)$. ANO rates in index and subsequent pregnancies did not differ. Index pregnancy adverse outcome was associated with a higher risk of repeat outcome: RR 3.09 (95\%CI:1.30, 7.34) for instrumental delivery, RR 2.20 (95\%CI:1.06, 4.61) for emergency Caesarean, RR 4.55 (95\%CI:3.03, 6.82) for LGA, RR 5.01 (95\%CI:2.73, 9.22) for SGA and RR 2.10 (95\%CI:1.53, 2.87) for composite ANO). The greatest risk factor for subsequent LGA (RR 3.13 (95\% CI:2.20, 4.47)), SGA (RR 4.71 $(95 \%$ CI:2.66, 8.36)) or composite ANO (RR 2.01 (95\%CI:1.46, 2.78)) was having the same outcome in the index pregnancy.

Conclusions: Women with GDM and an adverse outcome are at very high risk of the same complication in their subsequent GDM pregnancy, representing a high-risk group that should be targeted for directed management over routine care.

Funding: nil

Key Words: diabetes in pregnancy

\section{Tweetable abstract:}

Women with GDM and an adverse outcome are at very high risk of the same complication in their subsequent GDM pregnancy.

\section{INTRODUCTION}

Gestational diabetes (GDM) is defined as glucose intolerance first diagnosed in pregnancy ${ }^{(1)}$. Risk factors include maternal age, ethnicity, family history of diabetes and obesity. Notably, a history of prior GDM confers an estimated $30-60 \%$ risk of recurrent $\mathrm{GDM}^{(2)}(3-5)(6,7)$. 
GDM is associated with adverse effects for both mother and fetus, including pre-eclampsia, polyhydramnios, shoulder dystocia, preterm birth, increased rate of neonatal intensive care admission, neonatal hypoglycemia, jaundice and respiratory distress, small for gestational age (SGA) and large for gestational age (LGA) babies $^{(8,9)}$. The risk of these complications in a second GDM pregnancy has not been defined. Only three studies have examined the risk of maternal or fetal complications in recurrent $\mathrm{GDM}^{(10-12)}$.

One retrospective study of 389 women observed higher fasting glucose levels and pre-pregnancy BMI in the second GDM pregnancy compared to the first, a non-significant increase in LGA and no increase in adverse neonatal outcomes ${ }^{(10)}$. In another retrospective study, LGA rates were similar in pregnancies with first-time and recurrent $\mathrm{GDM}^{(12)}$. Both studies did not examine individual level data to determine if women having adverse outcomes in the first pregnancy had a higher risk of the same outcomes in their second pregnancyinformation which is pertinent to the practical management of women with recurrent GDM. In contrast, a third study of GDM pregnancy pairs found a higher rate of LGA in the subsequent pregnancy compared to the index $(22.4 \% \text { vs } 13.8 \%)^{(11)}$. $41.5 \%$ of women with LGA in the index pregnancy went on to have another LGA baby.

The aims of this study were to quantitate the risk of adverse delivery outcome (ADO) and adverse neonatal outcome (ANO) in consecutive GDM pregnancies. More specifically, we assessed the predictive value of adverse outcome in the index GDM pregnancy on the next GDM pregnancy, and the relationship with other risk factors such as maternal BMI, interpregnancy weight gain and interpregnancy interval. This is important as discerning risk factors conferring a worse outcome in women with a second GDM pregnancy will identify subgroups of women who might benefit from earlier GDM screening or more directed therapy in their next pregnancy.

\section{METHODS}

\section{Cohort}

This is a retrospective longitudinal study of 424 GDM pregnancy pairs, conducted in two centres: the Royal Hospital for Women (RHW), a tertiary maternity hospital in Eastern Sydney, and Blacktown-Mount Druitt Hospital (BMDH), a hospital in Western Sydney with the highest annual number of births statewide. Women who attended GDM clinics from 2003-2015 with more than one GDM pregnancy were identified. Each pregnancy pair comprised two consecutive singleton GDM pregnancies from the same woman ("index" and "subsequent" pregnancies). In women with more than two GDM pregnancies, each set of consecutive GDM pregnancies was considered a pregnancy pair- e.g. in a woman with three GDM pregnancies, the first and second pregnancy and the second and third pregnancy were each considered as pregnancy pairs.

Both centres used the Australasian Diabetes in Pregnancy Society diagnostic criteria at the time of a fasting plasma glucose [?]5.5 mmol/L and/or a 2-hour glucose [?] $8.0 \mathrm{mmol} / \mathrm{L}$ on the 2-hour $75 \mathrm{~g}$ oral glucose tolerance test (GTT), which was performed in women with a 1-hour plasma glucose of [?]7.8 mmol/L after a nonfasting glucose challenge at 24-28 weeks gestation. Screening for GDM was performed in the early second trimester in women with a history of GDM in a prior pregnancy, polycystic ovarian syndrome, BMI [?] 35 $\mathrm{kg} / \mathrm{m}^{2}$, maternal age [?] 40 years or a first-degree relative with type 2 diabetes, and repeated at 24-28 weeks if GDM was diagnosed at that stage.

Glucose targets were a fasting glucose of [?] $5.0 \mathrm{mmol} / \mathrm{L}$ and a 2-hour glucose of [?]7.0 mmol/L at the RHW, and a fasting glucose of [?]5.5 mmol/L and a 2-hour glucose of [?]7.0 mmol/L at BMDH. Women were referred to the diabetes educator, instructed on home blood glucose monitoring and a low glycemic index diet and encouraged to do 30 minutes of exercise per day. They attended one- to four- weekly appointments at the GDM clinic attended by endocrine doctors. Insulin was commenced in women who did not regularly meet their blood glucose targets. The diagnostic criteria, glucose targets and the principles of management of GDM remained consistent during the study period at both centres.

Demographic and outcome data

Data were obtained from in-house databases, medical files and the Obstetrix Clinical Database System 
(http://www.meridianhi.com/index.php/obstetrix), a statewide database that accesses data from the New South Wales Perinatal Data Collection, a population-based surveillance system covering all births in the state. Maternal data collected included age at estimated date of confinement, ethnicity, height, weight at booking-in, week of booking-in, week of diagnosis of GDM, results of the GTT, requirement for and starting date of insulin and/or metformin, mode of delivery and need for instrumental delivery. Preterm birth was defined as delivery before 37 weeks gestation. Early GDM was defined as GDM diagnosed before 22 weeks gestation. Instrumental delivery or emergency Caesarean section were considered adverse delivery outcomes (ADO).

Neonatal data included gestational age at delivery, sex, birth weight, shoulder dystocia and fetal or neonatal death. Birth centiles were calculated using the Perinatal Institute's customized centile calculator (https://www.gestation.net/birthweight centiles/birthweight centiles.htm) which accounts for maternal height, weight, ethnicity, parity, sex of the child and gestational age at birth, for an Australian population. LGA was defined as a birth weight centile [?]90\%, and SGA was defined as a birth weight centile [?]10\%. At the RHW, neonatal hypoglycemia was defined as a capillary blood glucose $<2.2 \mathrm{mmol} / \mathrm{L}$. At BMDH, neonatal hypoglycemia was recorded if this diagnosis had been entered into the Obstetrix database. The primary adverse neonatal outcomes (ANO) studied were LGA and SGA. In addition, a composite ANO was defined as the presence of at least one of the following: shoulder dystocia, perinatal death, LGA or SGA.

Ethics

This study was approved by the South Eastern Sydney Local Health District-Northern Network Human Research Ethics Committee.

\section{Statistical analysis}

Statistical analysis was performed using an SPSS 26.0 software package and SAS 9.4. Characteristics of index and subsequent pregnancies were compared using paired t-tests for parametrically distributed data and Wilcoxon signed-rank tests for non-parametrically distributed data. Differences in proportions of dichotomous variables between index and subsequent pregnancies were analysed using McNemar's test. Chi-squared tests were used to calculate the relative risk (RR) of adverse outcomes in subsequent pregnancies. Characteristics of subsequent pregnancies with and without LGA, with and without SGA, and with and without the composite neonatal outcome were compared using independent t-tests for parametrically distributed data, Mann-Whitney U tests for non-parametrically distributed data and chi-squared tests for dichotomous variables.

Binomial regression analysis was performed to estimate the RR of recurrent SGA, LGA or composite ANO in a subsequent pregnancy. Potential factors identified on univariate analysis were included in the model and backward stepwise removal was performed in order to identify independent predictors of each outcome of interest and their adjusted RR.

Results are expressed as mean and standard deviation for parametric data and median and interquartile range for non-parametric data, unless otherwise stated. Critical significance is taken at $5 \%$.

\section{RESULTS}

\section{Maternal characteristics}

424 pregnancy pairs were analysed: 170 pairs from RHW (centre 1) and 254 pregnancy pairs from BMDH (centre 2). A total of 807 pregnancies in 375 women were studied, with 31 women having three GDM pregnancies and five having four GDM pregnancies.

Maternal characteristics in index and subsequent GDM pregnancies are shown in Table 1. The mean age was $30.6 \pm 4.9$ years in the index pregnancy and $33.5 \pm 4.9$ years in the subsequent pregnancy. Booking-in weight and BMI were higher in the subsequent pregnancy $(\mathrm{p}<0.001)$, and GDM was diagnosed 3 weeks earlier $(\mathrm{p}<0.001)$ with a higher rate of early GDM $(42.5 \%$ vs $9.7 \%, \mathrm{p}<0.001)$. The rate of medication use (insulin, metformin or both) was higher in the subsequent pregnancy $(63.7 \%$ vs $54.0 \%, \mathrm{p}<0.001)$ and medication was 
started 3 weeks earlier $(\mathrm{p}<0.001)$. There were no differences in GTT results in the index versus subsequent pregnancy.

While there were some minor differences in maternal characteristics between the two centres, interpregnancy changes were generally comparable. The mean increment in age between index and subsequent pregnancies was slightly smaller in centre 1 versus centre $2(2.6 \pm 1.3$ vs $3.1 \pm 1.7$ years, $\mathrm{p}=0.001)$. Similarly, the mean increment in body weight at booking-in (the first antenatal visit) was smaller in centre 1 (1.8 \pm 5.7 vs $3.1 \pm 6.1$ $\mathrm{kg}, \mathrm{p}=0.03)$. There were no significant differences in interval changes between centres for other maternal parameters including BMI at booking-in and glucose levels on the GTT.

Adverse delivery outcomes (ADO)

Instrumental delivery ( $5 \%$ vs $13.9 \%, \mathrm{p}<0.001)$ and emergency Caesarean section $(7.1 \%$ vs $16.3 \%, \mathrm{p}<0.001)$ were decreased in the subsequent pregnancy. However, there was a higher rate of elective Caesarean section $(30.4 \%$ vs $17.0 \%, \mathrm{p}<0.001)$ and a lower rate of vaginal delivery $(62.3 \%$ vs $66.3 \%, \mathrm{p}=0.01)$ and induction of labour $(33.7 \%$ vs $47.2 \%, \mathrm{p}<0.001)$ (Table 1$)$.

Adverse neonatal outcomes (ANO)

There were no differences in the rates of SGA, LGA, fetal/neonatal death, neonatal hypoglycemia, or the composite ANO (death/dystocia/LGA/SGA) when index and subsequent GDM pregnancies were compared as a group (Table 1). Babies from subsequent pregnancies were delivered slightly earlier (38.5 \pm 1.4 vs 38.7 \pm 1.6 weeks gestation, $\mathrm{p}=0.02)$ than those from index pregnancies. While birth weight was increased in the subsequent pregnancy $(3392 \pm 587 \mathrm{~g}$ vs $3315 \pm 554 \mathrm{~g}, \mathrm{p}=0.005)$, customized birth centiles were similar (54 $(28-80) \%$ vs $50(27-77) \%, \mathrm{p}=0.23)$ (Table 1$)$.

\section{Risk of recurrent adverse delivery outcomes}

The risk of ADO in the subsequent pregnancy was greatly increased in those women who had ADO in their index pregnancies, with a 3 -fold risk of instrumental delivery in those women who required it in their index pregnancy, and a 2.2-fold risk of emergency Caesarean section compared to women who did not. Similarly, women who had early GDM, requirement for medication, or preterm birth in their index pregnancies were at much higher risk of developing the same outcomes in their subsequent pregnancy (Table 2).

\section{Risk of recurrent adverse neonatal outcomes}

While the rate of LGA or SGA was not different in index versus subsequent pregnancies as a group, the risk of these complications in their subsequent pregnancy was greatly increased in those women who had LGA or SGA in their index pregnancy compared to those who did not (Figure 1). For example, while the rate of LGA was similar in index and subsequent pregnancies (16.7\% vs $15.8 \%$, p=NS), the rate of LGA in the subsequent pregnancy was $45.1 \%$ in those women who had LGA in their index pregnancy, with a RR of 4.55 compared to women who did not. Likewise, while the rate of SGA was similar in index and subsequent pregnancies $(7.8 \%$ vs $8.7 \%, \mathrm{p}=\mathrm{NS})$, the rate of SGA in the subsequent pregnancy was $33.3 \%$ in women who had SGA in their index pregnancy, with a RR of 5.01 compared to women who did not (Figure 1). This greatly increased risk was also the case for the composite ANO (death/dystocia/LGA/SGA) (Table 2).

Conversely, having an SGA baby in the index GDM pregnancy was associated with a below average rate of LGA $(6.1 \%, n=2 / 33)$, and having prior LGA was associated with an SGA rate of only $1.4 \%(n=1 / 71)$ in the subsequent GDM pregnancy. Women with no LGA or SGA history had a $7.8 \%$ rate of SGA and $10.3 \%$ rate of LGA in their subsequent GDM pregnancy (Table 2).

Factors associated with $A N O$ in the subsequent GDM pregnancy

On univariate analysis, women with LGA in their subsequent GDM pregnancy were slightly younger with higher parity compared to those without LGA. They had a $17.5 \mathrm{~kg}$ greater median booking-in weight (84.5 (69.0-105.0) vs $67.0(58.0-82.0) \mathrm{kg}, \mathrm{p}<0.001)$, higher booking-in BMI (31.3 (26.9- 37.4)) vs 26.5 (23.1-32.0) $\left.\mathrm{kg} / \mathrm{m}^{2}, \mathrm{p}<0.001\right)$ and a $2.5 \mathrm{~kg}$ greater interpregnancy weight gain than women without LGA (4.7 $\pm 8.4 \mathrm{vs}$ 
$2.2 \pm 5.4 \mathrm{~kg}, \mathrm{p}=0.002)$, despite a similar interpregnancy interval. They had a higher fasting and two-hour glucose on the diagnostic GTT. $47.8 \%$ had LGA in their index pregnancy, whereas only $10.9 \%$ of women without LGA in the subsequent pregnancy had LGA in the index pregnancy $(\mathrm{p}<0.001)$ (Table 3$)$.

On univariate analysis, women with SGA in their subsequent GDM pregnancy had a longer interpregnancy interval $(3.9 \pm 2.1$ vs $2.8 \pm 1.5$ years, $\mathrm{p}<0.001)$ compared to women without SGA. $70.3 \%$ had SGA in their index pregnancy, versus $5.7 \%$ of women without SGA in their subsequent pregnancy $(\mathrm{p}<0.001)$. There was a trend to lower booking-in weight $(65.0(56.0-77.5)$ vs $71.0(59.3-88.0) \mathrm{kg}, \mathrm{p}=0.07)$ but no differences in booking-in BMI or interpregnancy weight change (Table 3).

On univariate analysis, women who had the composite ANO in the subsequent GDM pregnancy had a higher parity compared to those who did not. They had a $19.5 \mathrm{~kg}$ greater booking-in weight, higher booking-in BMI (29.7 (24.9-35.4) vs $\left.26.6(23.1-32.1) \mathrm{kg} / \mathrm{m}^{-2}, \mathrm{p}=0.001\right)$ and a $1.7 \mathrm{~kg}$ greater weight gain $(\mathrm{p}=0.01)$ between pregnancies. These women had a higher fasting and 2-hour glucose on the diagnostic GTT. 43.5\% had the composite ANO in their index pregnancy, compared to $21.2 \%$ of those without any ANO in their subsequent pregnancy $(\mathrm{p}<0.001)$ (Table 3$)$.

Based on results of univariate analysis, potential predictors of LGA in the subsequent pregnancy were included in a binomial regression model (prior LGA, BMI at booking-in, interpregnancy weight gain, and fasting glucose at diagnostic OGTT). After backward stepwise removal, LGA in the index pregnancy remained the strongest predictor of subsequent LGA, with a RR of 3.13 (95\%CI:2.20, 4.47, p<0.001) compared to women without prior LGA. Booking-in BMI showed a modest association with LGA outcome- RR 1.04 (95\%CI:1.02, $1.07, \mathrm{p}<0.001)$.

For the outcome of SGA in the subsequent pregnancy, prior SGA, interpregnancy interval and booking-in weight were included in the model. After adjustment, the RR of SGA in women with SGA in the index pregnancy was $4.71(95 \% \mathrm{CI}: 2.66,8.36, \mathrm{p}<0.001)$. For every one-year increase in the interpregnancy interval, the RR of SGA was $1.51(95 \% \mathrm{CI}: 1.19,1.91, \mathrm{p}<0.001)$

For the composite ANO, the regression model included prior composite ANO, booking-in BMI, interpregnancy weight gain, fasting glucose at diagnostic OGTT and Europid/non-Europid ethnicity. After adjustment, the RR of ANO was $2.01(95 \% \mathrm{CI}: 1.46,2.78, \mathrm{p}<0.001)$ in women with a prior history of ANO in the index pregnancy.

\section{DISCUSSION}

In this study of 424 pairs of consecutive GDM pregnancies, an ADO or ANO in the index GDM pregnancy conveyed a greatly increased risk of the same outcome in the subsequent GDM pregnancy. While these risks have been described in the general antenatal population, they have not been previously quantitated in GDM.

Compared to index GDM pregnancies, the rates of instrumental delivery and emergency Caesarean section were more than halved in subsequent pregnancies, with correspondingly increased rates of elective Caesarean section, lower rates of vaginal delivery and induction of labour. This could be explained by a greater consideration of elective Caesarean in women with a previous Caesarean section, and also be influenced by a history of ADO or LGA in the index pregnancy. But while ADOs were improved in subsequent pregnancies, the risk of having an ADO was still far greater in women with a history of the same ADO in the index pregnancy, with a RR of 3.09 for instrumental delivery and 2.20 for emergency Caesarean. These risks may justify a lower threshold for elective Caesarean in women with recurrent GDM and history of instrumental delivery or emergency Caesarean.

While delivery outcomes were improved in subsequent GDM pregnancies, ANO rates were unchanged in index versus subsequent pregnancies, with LGA rates of $\sim 16 \%$, SGA rates of $\sim 8 \%$ and overall composite ANO rates of $~ 26 \%$. Given that women with subsequent GDM pregnancies were older, had a higher BMI and were more likely to require medication, it could be hypothesised that they should have had a higher rate of adverse outcomes, which was not the case. One explanation could be that women were diagnosed earlier due to earlier screening which may have affected ANO rates. 
Three retrospective studies have examined the comparative rates of LGA in first and second GDM pregnancies ${ }^{(10-12)}$, although none have analyzed detailed individual-level data across consecutive pregnancies. Similar to our study, a study of 389 predominantly Mexican-American women found no difference in rates of LGA ${ }^{(10)}$ with a $15.6 \%$ rate of LGA in the first GDM pregnancy compared to $19.9 \%$ in the second GDM pregnancy. Another retrospective study of pregnancy-pairs ${ }^{(12)}$. also found that LGA and SGA rates were not significantly different between pregnancies with first time GDM and those with recurrent GDM. However, the authors also did not quantitate the risk of recurrent adverse outcomes from one GDM pregnancy to the next.

Only one study has quantitated the risk of recurrent adverse outcome in recurrent GDM pregnancy pairs ${ }^{(11)}$. In contrast to our study, the LGA rate increased in the second GDM pregnancy $(22.4 \%$ vs $13.8 \%, \mathrm{p}<0.05)$. The risk of recurrent LGA was $55.7 \%$, comparable to our rate of $45.1 \%$. While this population-based study had a large of number of pregnancy pairs, it did not examine other ANOs such as SGA and fetal or neonatal death, and detailed clinical information such as timing of diagnosis of GDM, medications, results of the GTT, maternal BMI and interpregnancy interval, were not included in the analyses. Thus, they were not able to evaluate for effects of other factors associated with increased risk of recurrent LGA.

Our study lends a new perspective by tracking the incidence of ANOs in individual women over consecutive GDM pregnancies. The RR of repeat outcome for women with LGA, SGA or any ANO in their GDM pregnancy was 4.5 fold, 5.0 and 2.1 respectively. Put another way, nearly half of women with LGA, $70 \%$ of women with SGA and $44 \%$ of women with the composite ANO in their subsequent pregnancy had the same outcome in their index pregnancy. Thus while ANO rates were similar in index and subsequent pregnancies as a group, a substantial proportion of adverse outcomes were occurring in the same women. Of additional interest is the very low risk of SGA in women with prior LGA, and the low risk of LGA in women with prior SGA.

Multivariate analysis of ANO in the subsequent pregnancy showed that having the same outcome in the index pregnancy was by far the strongest risk factor, with a 3.1-fold for LGA, 4.7-fold for SGA and 2-fold for the composite ANO. In LGA, this risk far outweighed that of maternal BMI, a well-established risk factor for LGA ${ }^{(13,14)}$. In SGA, this risk far outweighed that associated with increasing interpregnancy interval.

The risks of recurrent LGA or SGA have not been previously described in GDM. Our calculated risks are similar in magnitude to the five-fold risk observed in general obstetric cohorts for LGA ${ }^{(15)(16)}$ as well as for SGA $(17,18)$. Moreover, severity of GDM based on the GTT results, need for medication and timing of diagnosis were not associated with subsequent pregnancy outcomes. While on the surface these data may suggest that GDM does not impact greatly on risk of recurrent ANOs, we were not able to include the modifiable factors of gestational weight gain and a measure of glycaemia such as HbA1c in our model, and cannot discount the importance of weight and glycemic management.

Limitations of this study include unavailable data on maternal smoking status, gestational weight gain and hypertensive disorders. There were slight differences in glucose targets between centres and slight differences in population demographics although reassuringly, interpregnancy changes did not differ between centres. We relied on medication requirement as a surrogate marker of glycaemia. It is possible some of the participants may have had undiagnosed type 2 diabetes.

Strengths of this study included the inclusion of consecutive GDM pregnancy pairs and the analysis of longitudinal data in individual patients that allowed us to assess risk of adverse outcomes in the context of previous complications. We were able to adjust for relevant clinical covariates including interpregnancy duration and interpregnancy weight gain, both pertinent to recurrent GDM. The definitions of LGA and SGA were based on customised centiles for an Australian population.

According to current standards, diagnostic criteria, glucose targets and weight gain targets are applicable to all GDM women, irrespective of their history of ADO/ANO. Given the high frequency of repeat complications, should these criteria be tightened for women with prior LGA, or relaxed for women with a history of SGA? Would early detection of GDM be effective in prevention of LGA, or could it be detrimental in those 
with prior SGA? Further studies are required to provide evidence-based guidelines for managing recurrent GDM.

\section{CONCLUSION}

While rates of adverse neonatal outcomes were similar in index and subsequent GDM pregnancies, the risk was greatly increased in women who had an adverse outcome in the first pregnancy. This is despite decreased rates of adverse delivery outcomes. Our study identifies a group of women with recurrent GDM and previous LGA, who may stand to gain the most from intensive management of their glucose levels and weight. It also discerns a group of women with recurrent GDM and previous SGA in whom intensive or early therapy might potentially be unwarranted, given the high risk of recurrent SGA and the low risk of LGA.

\section{Acknowledgments:}

None

\section{Disclosure of interests:}

None

\section{Contribution to authorship:}

SLL designed the study, collected and analysed the data and reviewed the manuscript. AC and JK collected and analysed the data. SH collected the data. WH collected the data and reviewed the manuscript. SML designed the study, collected and analysed the data and wrote the manuscript.

\section{Details of ethics approval:}

This study was approved by the South Eastern Sydney Local Health District Northern Network Human Research Ethics Committee (ref no. 15/314, approved 07/01/2016).

\section{Funding:}

None

\section{References:}

1. Metzger BE. Summary and recommendations of the Third International Workshop-Conference on Gestational Diabetes Mellitus. Diabetes. 1991;40 Suppl 2:197-201.

2. Kim C, Berger DK, Chamany S. Recurrence of gestational diabetes mellitus: a systematic review. Diabetes Care. 2007;30(5):1314-9.

3. MacNeill S, Dodds L, Hamilton DC, Armson BA, VandenHof M. Rates and risk factors for recurrence of gestational diabetes. Diabetes Care. 2001;24(4):659-62.

4. Bernstein JA, Quinn E, Ameli O, Craig M, Heeren T, Lee-Parritz A, et al. Follow-up after gestational diabetes: a fixable gap in women's preventive healthcare. BMJ Open Diabetes Res Care. 2017;5(1):e000445.

5. Gaudier FL, Hauth JC, Poist M, Corbett D, Cliver SP. Recurrence of gestational diabetes mellitus. Obstet Gynecol. 1992;80(5):755-8.

6. Moses RG. The recurrence rate of gestational diabetes in subsequent pregnancies. Diabetes Care. 1996;19(12):1348-50.

7. Major CA, deVeciana M, Weeks J, Morgan MA. Recurrence of gestational diabetes: who is at risk? Am J Obstet Gynecol. 1998;179(4):1038-42.

8. Adams KM, Li H, Nelson RL, Ogburn PL, Jr., Danilenko-Dixon DR. Sequelae of unrecognized gestational diabetes. Am J Obstet Gynecol. 1998;178(6):1321-32. 
9. Xiong X, Saunders LD, Wang FL, Demianczuk NN. Gestational diabetes mellitus: prevalence, risk factors, maternal and infant outcomes. Int J Gynaecol Obstet. 2001;75(3):221-8.

10. Yogev Y, Langer O. Recurrence of gestational diabetes: pregnancy outcome and birth weight diversity. J Matern Fetal Neonatal Med. 2004;15(1):56-60.

11. Kim SY, Kotelchuck M, Wilson HG, Diop H, Shapiro-Mendoza CK, England LJ. Prevalence of Adverse Pregnancy Outcomes, by Maternal Diabetes Status at First and Second Deliveries, Massachusetts, 1998-2007. Prev Chronic Dis. 2015;12:E218.

12. Boghossian NS, Yeung E, Albert PS, Mendola P, Laughon SK, Hinkle SN, et al. Changes in diabetes status between pregnancies and impact on subsequent newborn outcomes. Am J Obstet Gynecol. 2014;210(5):431 e1-14.

13. Catalano PM, McIntyre HD, Cruickshank JK, McCance DR, Dyer AR, Metzger BE, et al. The hyperglycemia and adverse pregnancy outcome study: associations of GDM and obesity with pregnancy outcomes. Diabetes Care. 2012;35(4):780-6.

14. Barbour LA. Metabolic Culprits in Obese Pregnancies and Gestational Diabetes Mellitus: Big Babies, Big Twists, Big Picture : The 2018 Norbert Freinkel Award Lecture. Diabetes Care. 2019;42(5):718-26.

15. Hiersch L, Shinar S, Melamed N, Aviram A, Hadar E, Yogev Y, et al. Birthweight and large for gestational age trends in non-diabetic women with three consecutive term deliveries. Arch Gynecol Obstet. 2018;298(4):725-30.

16. Wallace JM, Bhattacharya S, Campbell DM, Horgan GW. Inter-Pregnancy Weight Change and the Risk of Recurrent Pregnancy Complications. PLoS One. 2016;11(5):e0154812.

17. Hinkle SN, Albert PS, Mendola P, Sjaarda LA, Boghossian NS, Yeung E, et al. Differences in risk factors for incident and recurrent small-for-gestational-age birthweight: a hospital-based cohort study. BJOG. 2014;121(9):1080-8; discussion 9.

18. Manzanares S, Maroto-Martin MT, Naveiro M, Sanchez-Gila M, Lopez-Criado S, Puertas A. Risk of recurrence of small-for-gestational-age foetus after first pregnancy. J Obstet Gynaecol. 2017;37(6):723-6.

\section{Table and Figure Legends:}

Table 1: Characteristics of index and subsequent GDM pregnancies. Data expressed as mean (SD), median (IQR) or n (\%).

Table 2: Rate and relative risk of recurrent maternal and neonatal outcomes in the subsequent GDM pregnancy.

${ }^{a}$ in women with this outcome in the index pregnancy

b compared to women without this outcome in their index pregnancy

Table 3: Characteristics of subsequent GDM pregnancies with and without LGA, SGA or the composite neonatal outcome. Data expressed as mean (SD), median (IQR) or n (\%).

Figure 1: SGA and LGA outcomes in index and subsequent pregnancies. Data expressed as n (\%).

\begin{tabular}{lll}
\hline & GDM pregnancy pairs $(\mathrm{n}=424)$ & GDM pregnancy pai \\
\hline & Index & Subsequent \\
Age (years) & $30.6(4.9)$ & $33.5(4.9)$ \\
Booking-in weight $(\mathrm{kg})$ & $67(58.0,82.0)$ & $70(59.0,87.0)$ \\
Booking-in BMI $\left(\mathrm{kg} / \mathrm{m}^{2}\right)$ & $26.2(22.6,31.6)$ & $27.1(23.4,32.5)$ \\
Week of booking & $12.4(6.0)$ & $12.8(5.7)$ \\
Ethnicity (n,\%) & &
\end{tabular}




\begin{tabular}{|c|c|c|}
\hline & GDM pregnancy pairs $(\mathrm{n}=424)$ & GDM pregnancy pai \\
\hline -Europid & $178(42.0)$ & \\
\hline -East Asia & $89(21.0)$ & \\
\hline -South Asia & $68(16.0)$ & \\
\hline -Middle East & $57(13.4)$ & \\
\hline -Other & $32(7.6)$ & \\
\hline \multicolumn{3}{|l|}{ Parity (n,\%) } \\
\hline 0 & $238(56.1)$ & - \\
\hline 1 & $104(24.5)$ & $223(52.7)$ \\
\hline 2 & $45(10.6)$ & $110(26.0)$ \\
\hline$>2$ & $37(8.7)$ & $90(21.3)$ \\
\hline Week of GDM diagnosis & $27(25,29)$ & $24(16,27)$ \\
\hline \multicolumn{3}{|l|}{ Early vs late GDM (n,\%) } \\
\hline -early & $41(9.7)$ & $180(42.5)$ \\
\hline -late & $383(90.3)$ & $244(57.5)$ \\
\hline GTT- fasting glucose $(\mathrm{mmol} / \mathrm{L})$ & $4.9(0.9)$ & $5.0(1.0)$ \\
\hline GTT- 2 hour glucose (mmol/L) & $9.0(1.4)$ & $8.9(1.7)$ \\
\hline \multicolumn{3}{|l|}{ Medication required $(\%)$} \\
\hline -yes & $229(54.0)$ & $270(63.7)$ \\
\hline- no & $195(46.0)$ & $154(36.3)$ \\
\hline Week medication started & $30(28,33)$ & $27(21,30)$ \\
\hline \multicolumn{3}{|l|}{ Mode of delivery (\%) } \\
\hline -vaginal birth & $281(66.3)$ & $264(62.3)$ \\
\hline -Caesarean section & $143(33.7)$ & $160(37.7)$ \\
\hline \multicolumn{3}{|l|}{ Induction of labour (n, \%) } \\
\hline -yes & $200(47.2)$ & $143(33.7)$ \\
\hline -no & $224(52.8)$ & $281(66.3)$ \\
\hline \multicolumn{3}{|l|}{ Instrumental delivery (n, \%) } \\
\hline -yes & $59(13.9)$ & $21(5.0)$ \\
\hline- no & $365(86.1)$ & $403(95.0)$ \\
\hline \multicolumn{3}{|l|}{ Emergency Caesarean (n, \%) } \\
\hline -yes & $69(16.3)$ & $30(7.1)$ \\
\hline- no & $355(83.7)$ & $394(92.9)$ \\
\hline \multicolumn{3}{|l|}{ Elective Caesarean (n, \%) } \\
\hline -yes & $72(17.0)$ & $129(30.4)$ \\
\hline -no & $352(83.0)$ & $295(69.6)$ \\
\hline Gestation at delivery (weeks) & $38.7(1.6)$ & $38.5(1.4)$ \\
\hline \multicolumn{3}{|l|}{ Delivery $<37$ wks } \\
\hline & $30(7.1)$ & $40(9.4)$ \\
\hline & $394(92.9)$ & $384(90.6)$ \\
\hline Birth weight $(\mathrm{g})$ & $3315(554)$ & $3392(587)$ \\
\hline Birth weight centile (\%) & $50(27.77)$ & $54(28,80)$ \\
\hline \multicolumn{3}{|l|}{ SGA $(\%)$} \\
\hline -yes & $33(7.8)$ & $37(8.7)$ \\
\hline -no & $391(92.2)$ & $387(91.3)$ \\
\hline \multicolumn{3}{|l|}{ LGA (\%) } \\
\hline -yes & $71(16.7)$ & $67(15.8)$ \\
\hline- no & $353(83.3)$ & $357(84.2)$ \\
\hline Birth length $(\mathrm{cm})$ & $50.1(3.0)$ & $50.3(2.6)$ \\
\hline \multicolumn{3}{|l|}{ Fetal/neonatal death (n, \%) } \\
\hline -yes & $421(99.3)$ & $423(99.8)$ \\
\hline
\end{tabular}




\begin{tabular}{lll}
\hline & GDM pregnancy pairs (n=424) & GDM pregnancy pai \\
\hline -no & $3(0.7)$ & $1(0.2)$ \\
$\begin{array}{l}\text { Dystocia (n, \%) } \\
\text {-yes }\end{array}$ & $17(4.0)$ & $8(1.9)$ \\
-no & $407(96.0)$ & $416(98.1)$ \\
Neonatal hypoglycemia (n, \%) & & \\
-yes & $57(13.4)$ & $69(16.3)$ \\
-no & $367(86.6)$ & $355(83.7)$ \\
Composite neonatal outcome (death/dystocia/LGA/ SGA) (n, \%) & & $108(25.5)$ \\
-yes & $114(26.9)$ & $316(74.5)$ \\
-no & $310(73.1)$ & \\
\hline
\end{tabular}

Table 1: Characteristics of index and subsequent GDM pregnancies. Data expressed as mean (SD), median (IQR) or n (\%).

\begin{tabular}{lll}
\hline Outcome & Rate $^{\mathrm{a}}(\%)$ & ${\text { Relative risk }(95 \% \mathrm{CI})^{\mathrm{b}} \text { in subsequent pregnancy }}$ in \\
\hline Early GDM & 67.5 & $1.65(1.29,2.11)$ \\
GDM requiring medication & 87.3 & $2.40(1.98,2.91)$ \\
Instrumental delivery & 11.9 & $3.09(1.30,7.34)$ \\
Emergency Caesarean section & 13.0 & $2.20(1.06,4.61)$ \\
SGA & 33.3 & $5.01(2.73,9.22)$ \\
LGA & 45.1 & $4.55(3.03,6.82)$ \\
Preterm birth & 33.3 & $4.38(2.37,8.07)$ \\
Composite neonatal outcome (death/dystocia/LGA/ SGA) & 41.2 & $2.10(1.53,2.87)$ \\
\hline
\end{tabular}

Table 2: Rate and relative risk of recurrent maternal and neonatal outcomes in the subsequent GDM pregnancy

a in women with this outcome in the index pregnancy

b compared to women without this outcome in their index pregnancy

\begin{tabular}{|c|c|c|c|c|c|c|c|c|}
\hline & $\begin{array}{l}\text { No } \\
\text { LGA }\end{array}$ & LGA & $p$ value & $\begin{array}{l}\text { No } \\
\text { SGA }\end{array}$ & SGA & $p$ value & $\begin{array}{l}\text { No } \\
\text { neona- } \\
\text { tal } \\
\text { com- } \\
\text { posite } \\
\text { outcome }\end{array}$ & $\begin{array}{l}\text { Neonatal } \\
\text { com- } \\
\text { posite } \\
\text { outcome }\end{array}$ \\
\hline $\begin{array}{l}\text { Age } \\
\text { (years) }\end{array}$ & $\begin{array}{l}33.7 \\
(4.7)\end{array}$ & $\begin{array}{l}32.4 \\
(5.6)\end{array}$ & 0.02 & $\begin{array}{l}33.5 \\
(5.0)\end{array}$ & $\begin{array}{l}33.6 \\
(4.0)\end{array}$ & 0.94 & $\begin{array}{l}33.7 \\
(4.8)\end{array}$ & $\begin{array}{l}32.9 \\
(5.0)\end{array}$ \\
\hline $\begin{array}{l}\text { Interval } \\
\text { be- } \\
\text { tween } \\
\text { preg- } \\
\text { nancies } \\
\text { (years) }\end{array}$ & $\begin{array}{l}3.0 \\
(1.5)\end{array}$ & $\begin{array}{l}2.7 \\
(1.7)\end{array}$ & 0.28 & $\begin{array}{l}2.8 \\
(1.5)\end{array}$ & $\begin{array}{l}3.9 \\
(2.1)\end{array}$ & $<0.001$ & $\begin{array}{l}2.8 \\
(1.4)\end{array}$ & $\begin{array}{l}3.1 \\
(1.9)\end{array}$ \\
\hline $\begin{array}{l}\text { Booking- } \\
\text { in weight } \\
(\mathrm{kg})\end{array}$ & $\begin{array}{l}67.0 \\
(58.0,82.0)\end{array}$ & $\begin{array}{l}84.5 \\
(69,105)\end{array}$ & $<0.001$ & $\begin{array}{l}71.0 \\
(59.3,88.0)\end{array}$ & $\begin{array}{l}65.0 \\
(56.0,77.5)\end{array}$ & 0.07 & $\begin{array}{l}58.0(68.0, \\
84.0)\end{array}$ & $\begin{array}{l}77.5 \\
(64.0,93.8)\end{array}$ \\
\hline
\end{tabular}




\begin{tabular}{|c|c|c|c|c|c|c|c|c|}
\hline & $\begin{array}{l}\text { No } \\
\text { LGA }\end{array}$ & LGA & $p$ value & $\begin{array}{l}\text { No } \\
\text { SGA }\end{array}$ & SGA & $p$ value & $\begin{array}{l}\text { No } \\
\text { neona- } \\
\text { tal } \\
\text { com- } \\
\text { posite } \\
\text { outcome }\end{array}$ & $\begin{array}{l}\text { Neonatal } \\
\text { com- } \\
\text { posite } \\
\text { outcome }\end{array}$ \\
\hline $\begin{array}{l}\text { Weight } \\
\text { change } \\
\text { be- } \\
\text { tween } \\
\text { preg- } \\
\text { nancies } \\
(\mathrm{kg})\end{array}$ & $\begin{array}{l}2.2 \\
(5.4)\end{array}$ & $\begin{array}{l}4.7 \\
(8.4)\end{array}$ & 0.002 & $\begin{array}{l}2.6 \\
(6.1)\end{array}$ & $\begin{array}{l}2.4 \\
(5.5)\end{array}$ & 0.87 & $\begin{array}{l}2.2 \\
(5.4)\end{array}$ & $\begin{array}{l}3.9 \\
(7.9)\end{array}$ \\
\hline $\begin{array}{l}\text { Booking- } \\
\text { in BMI } \\
\left(\mathrm{kg} / \mathrm{m}^{2}\right)\end{array}$ & $\begin{array}{l}26.5 \\
(23.1,32.0)\end{array}$ & $\begin{array}{l}31.3(26.9 \\
37.4)\end{array}$ & $<0.001$ & $\begin{array}{l}27.1 \\
(23,4,32.8)\end{array}$ & $\begin{array}{l}23.2 \\
(25.8,31.6)\end{array}$ & 0.46 & $\begin{array}{l}26.6 \\
(23.1,32.1)\end{array}$ & $\begin{array}{l}29.7 \\
(24.9,35.4)\end{array}$ \\
\hline $\begin{array}{l}\text { Ethnicity } \\
(\mathrm{n}, \%)\end{array}$ & & & 0.08 & & & 0.11 & & \\
\hline Europid & 38.4 & 50.7 & & 41.6 & 27.0 & & 39.6 & 42.6 \\
\hline $\begin{array}{l}\text {-Non- } \\
\text { Europid }\end{array}$ & 61.6 & 49.3 & & 58.4 & 73.0 & & 60.4 & 57.4 \\
\hline $\begin{array}{l}\text { Parity } \\
(\mathrm{n}, \%)\end{array}$ & & & 0.002 & & & 0.87 & & \\
\hline 1 & 55.9 & 35.8 & & 52.3 & 56.8 & & 56.2 & 42.6 \\
\hline 2 & 25.6 & 28.4 & & 26.2 & 24.3 & & 25.4 & 27.8 \\
\hline$>2$ & 18.9 & 35.8 & & 21.5 & 18.9 & & 18.4 & 29.6 \\
\hline $\begin{array}{l}\text { Week of } \\
\text { GDM } \\
\text { diagnosis }\end{array}$ & $\begin{array}{l}24.0 \\
(17.0,27.0)\end{array}$ & $\begin{array}{l}23.5 \\
(14.8,28.0)\end{array}$ & 0.89 & $\begin{array}{l}24.0 \\
(16.0,27.0)\end{array}$ & $\begin{array}{l}20.0 \\
(15.5,26.0)\end{array}$ & 0.10 & $\begin{array}{l}24.0 \\
(17.0,27.0)\end{array}$ & $\begin{array}{l}15.0 \\
(21.0,27.0)\end{array}$ \\
\hline $\begin{array}{l}\text { Early } \\
\text { vs late } \\
\text { GDM } \\
(\mathrm{n}, \%)\end{array}$ & & & 0.42 & & & 0.22 & & \\
\hline -early & 42.7 & 48.5 & & 42.6 & 54.1 & & 41.2 & 50.5 \\
\hline -late & 57.3 & 51.5 & & 57.4 & 45.9 & & 58.8 & 49.5 \\
\hline $\begin{array}{l}\text { GTT- } \\
\text { fasting } \\
\text { glucose } \\
(\mathrm{mmol} / \mathrm{L})\end{array}$ & $\begin{array}{l}4.9 \\
(0.8)\end{array}$ & $\begin{array}{l}5.6 \\
(1.5)\end{array}$ & $<0.001$ & $\begin{array}{l}5.0 \\
(1.0)\end{array}$ & $\begin{array}{l}4.7 \\
(0.7)\end{array}$ & 0.27 & $\begin{array}{l}4.9 \\
(0.9)\end{array}$ & $\begin{array}{l}5.2 \\
(1.3)\end{array}$ \\
\hline $\begin{array}{l}\text { GTT- } \\
2 \text { hour } \\
\text { glucose } \\
(\mathrm{mmol} / \mathrm{L})\end{array}$ & $\begin{array}{l}8.8 \\
(1.6)\end{array}$ & $\begin{array}{l}9.7 \\
(2.2)\end{array}$ & 0.002 & $\begin{array}{l}9.0 \\
(1.7)\end{array}$ & $\begin{array}{l}8.8 \\
(1.5)\end{array}$ & 0.71 & $\begin{array}{l}8.8 \\
(1.6)\end{array}$ & $\begin{array}{l}9.3 \\
(2.0)\end{array}$ \\
\hline $\begin{array}{l}\text { Medication } \\
\text { re- } \\
\text { quired } \\
(\%)\end{array}$ & & & 0.17 & & & 0.72 & & \\
\hline -yes & 62.5 & 71.6 & & 63.3 & 67.6 & & 61.7 & 70.4 \\
\hline -no & 37.5 & 28.4 & & 36.4 & 32.4 & & 38.3 & 29.6 \\
\hline
\end{tabular}




\begin{tabular}{|c|c|c|c|c|c|c|c|c|}
\hline & $\begin{array}{l}\text { No } \\
\text { LGA }\end{array}$ & LGA & $p$ value & $\begin{array}{l}\text { No } \\
\text { SGA }\end{array}$ & SGA & $p$ value & $\begin{array}{l}\text { No } \\
\text { neona- } \\
\text { tal } \\
\text { com- } \\
\text { posite } \\
\text { outcome }\end{array}$ & $\begin{array}{l}\text { Neonatal } \\
\text { com- } \\
\text { posite } \\
\text { outcome }\end{array}$ \\
\hline $\begin{array}{l}\text { Same } \\
\text { out- } \\
\text { come } \\
\text { in pre- } \\
\text { vious } \\
\text { GDM } \\
\text { preg }\end{array}$ & & & $<0.001$ & & & $<0.001$ & & \\
\hline -yes & 10.9 & 47.8 & & 5.7 & 70.3 & & 21.2 & 43.5 \\
\hline -no & 89.1 & 52.2 & & 94.3 & 29.7 & & 78.8 & 56.5 \\
\hline
\end{tabular}

Table 3: Characteristics of subsequent GDM pregnancies with and without LGA, SGA or the composite neonatal outcome. Data expressed as mean (SD), median (IQR) or n (\%).

\begin{tabular}{|c|c|c|c|c|c|c|c|c|}
\hline \multicolumn{9}{|c|}{ Index pregnancy $(n=424)$} \\
\hline \multicolumn{3}{|c|}{$\begin{array}{l}\text { SGA } \\
33(7.8)\end{array}$} & \multicolumn{3}{|c|}{$\begin{array}{c}\text { Normal } \\
320(75.5)\end{array}$} & \multicolumn{3}{|c|}{$\begin{array}{l}\text { LGA } \\
71(16.7)\end{array}$} \\
\hline & 5 & & & 5 & & & 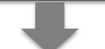 & \\
\hline $\begin{array}{c}\text { SGA } \\
11(33.3)\end{array}$ & $\begin{array}{l}\text { Normal } \\
20(60.6)\end{array}$ & $\begin{array}{l}\text { LGA } \\
2(6.1)\end{array}$ & $\begin{array}{c}\text { SGA } \\
25(7.8)\end{array}$ & $\begin{array}{l}\text { Normal } \\
262(81.9)\end{array}$ & $\begin{array}{c}\text { LGA } \\
33(10.3)\end{array}$ & $\begin{array}{l}\text { SGA } \\
1(1.4)\end{array}$ & $\begin{array}{l}\text { Normal } \\
38(53.5)\end{array}$ & $\begin{array}{c}\text { LGA } \\
32(45.1)\end{array}$ \\
\hline
\end{tabular}

Subsequent pregnancy $(n=424)$ 